\title{
ГОРОДСКОЕ НАСЕЛЕНИЕ ЗАПАДНОЙ СИБИРИ
}

\section{Рецензия на книгу «Городское население Западной \\ Сибири в 1960-1980-е годы: Историко-демографическое исследование»}

\section{ГЕННАДИЙ КОРНИЛОВ}

\begin{abstract}
В монографии исследованы демографические итоги урабанизационного перехода в Западной Сибири в условиях стабильного сочиально-экономического и политического развития странь после сочиильных катастроф и катаклизмов первой половины ХХ столетия. На обширном материале источников проанализированы развитие больших, средних и мальх городских поселений, динамика численности и национального состава горожан, этнодемографических процессов, возрастной структуры. В ходе изучения демографической модернизации Западной Сибири выявлены основные факторы и причины колебаний рождаемости и смертности, особенности эпидемиологического перехода. Большое внимание уделено исследованию миграџионного движения населения, в том числе в разных категориях городских поселений, межтерриториальных пространственных перемещений.
\end{abstract}

Ключевые слова: историческая демография, Сибирь, город, воспроизводство населения, миграция.

Историческая демография является сравнительно новым направлением научных исследований, особенно на региональных материалах. Первые опубликованные в данном ключе работы появились еще в 1950-е годы, и чаще всего их авторами являлись не историки, а демографы. Позднее стали появляться труды собственно историков (Ю.А. Поляков, В.Б. Жиромская, В.М. Кабузан, Н.А. Араловец, Д.К. Шелестов). В Сибири изучение проблем исторической демографии тесно связано с именами Н.И Платунова, В.А. Исупова, Н.Я. Гущина, В.А. Зверева и других.

В последние десятилетия число историко-демографических работ значительно увеличилось. Выросло понимание того, что изучение социально-экономических, политических и культурных процессов должно опираться на ретроспективный анализ демографических изменений в обществе. Именно поэтому в центре внимания историков оказались важнейшие проблемы демографии, такие как численность, возрастной состав, воспроизводство населения.

Изучение исторической динамики народонаселения на востоке страны, в том числе в Западной Сибири, представляет особый интерес. В работах ученых давно замечено, что освоение огромного, обладающего большими запасами биологических, земельных, водных и минеральных ресурсов, и в то же время с суровым климатом края шло интенсивно и подчинялось собственной логике. Его размеры, удаленность и малонаселенность, слаборазвитая социальная и транспортная инфраструктура предопределили формирование особых характеристик воспроизводственных и миграционных процессов, в том числе урбанизации, которые по-прежнему недостаточно изучены.

ГЕННАДИЙ ЕГОРОВИЧ КОРНИЛОВ (genakorn@mail.ru), ИНСТИТУТ ИСТОРИИ И АРХЕОЛОГИИ УРАЛЬСКОГО ОТДЕЛЕНИЯ РАН, РОССИЯ. 
В книге О. Дашинамжилова ${ }^{1}$ акцентировано внимание на актуальности исследования городов Сибири в связи с современной государственной политикой «разворота на Восток», в рамках которой предполагается интенсификация торговоэкономических связей со странами Азиатско-Тихоокеанского региона и вовлечение в хозяйственный оборот новых природных ресурсов сибирских и дальневосточных территорий. Однако политика с похожими задачами уже была реализована Советским Союзом в послевоенный период в рамках «ускоренного развития восточных районов». В Западной Сибири был сформирован Западно-Сибирский нефтегазовый комплекс (ЗСНГК), возведены крупные промышленные предприятия, построены разветвленная транспортная инфраструктура и сеть новых городов и поселков городского типа. Из этого следует, что изучение хозяйственно-демографического развития Западной Сибири в 1960 1980-е годы, особенно ее городов, ставших опорными пунктами освоения топливноэнергетических и минеральных ресурсов, представляет немалый научный, а также практический интерес.

Выбор Западной Сибири обоснован ее высокой ролью в хозяйственном развитии страны. Территориально-географическое положение, близость к Казахстану и Средней Азии оказали весомое воздействие на местную демографическую ситуацию. Уникальность Западной Сибири заключается в том, что становление сети ее городских поселений в $\mathrm{XX}$ столетии происходило под знаком государственных проектов, значение которых в рамках общесоюзной экономики было очень велико: Урало-Кузнецкого комбината, Западно-Сибирского нефтегазового комплекса. Большое влияние на систему городского расселения оказала эвакуация в годы войны, когда по числу перемещенных промышленных предприятий Западная Сибирь после Урала заняла лидирующие позиции среди экономических районов и республик востока СССР.

Исследование О.Б. Дашинамжилова стало одной из первых работ, выполненных в историко-демографическом аспекте, где в комплексе проанализированы численность, возрастной и национальный состав, естественное движение и миграция городского населения в рассматриваемый период. Автор оригинально подошел к решению задач концептуально-теоретического характера. Известно, что факторы миграции, рождаемости и смертности не полностью совпадают. До сих пор так и не было разработано теории, которая во всех взаимосвязях могла бы объяснить перемены, происходившие одновременно в численности, воспроизводстве и пространственных перемещениях населения. В работе подчеркивается, что изучение только рождаемости и смертности не является достаточным, так как миграции в динамике численности горожан играли высокую роль. Именно поэтому исходными теоретическими предпосылками книги стали две концепции - теории урабанизационного и демографического переходов (с. 24-25).

Согласно первой из них урбанизация в РСФСР делилась на две стадии: экстенсивную и интенсивную. Для интенсивной стадии, которая начинается с конца 1950 х годов (когда доля горожан превысила половину всего населения РСФСР), в отличие от экстенсивной присущи снижение масштабов увеличения численности и удельного веса

\footnotetext{
${ }^{1}$ Далее при отсылке к этой книге будет даваться только номер страницы или главы.
} 
городского населения, сокращение размеров миграционного прироста городов и увеличение интенсивности межгородских перемещений, уменьшение градообразовательной активности и опережающий рост горожан в наиболее крупных городах. Если теория урабанизационного перехода рассматривала главным образом изменения в численности и миграции городского населения, то демографического перехода - в его воспроизводстве, рождаемости и смертности.

При этом О.Б. Дашинамжилов заведомо рассматривает воспроизводственные процессы не как механические, происходящие сами по себе, а в тесной связи с историческим контекстом. К несомненным плюсам работы можно отнести принципы анализа собственно исторического контекста, который, несмотря на свою динамичность и вариативность, представлен преимущественно системно, структурно распределенным на факторы. Такой подход формирует ключевой в монографии тезис, что демографическая модернизация является итогом взаимодействия множества факторов, во многом идентичных в тех странах, где шел этот процесс, а потому и приведший к сходным результатам. Одновременно он оправдывает применение принципа историзма, позволяющего включить демографические показатели в содержательное историческое целое, связать их с региональной спецификой экономического, культурного развития, социальной структурой общества, его динамикой и др.

Важным условием успешного решения задач исторической демографии является не только высокая квалификация в вопросах истории и знание ее методов. Историкам, занимающимся проблемами демографии, необходимо хорошее знание методологии и методики демографических исследований. Работа показательна с точки зрения высокого уровня владения автором подобным инструментарием. Анализ воспроизводственных процессов, демографического перехода произведен с использованием индексного метода, методов условного поколения. Хорошей проработанностью методик отличается раздел, посвященный миграционному движению населения.

Для решения поставленных задач привлечено большое количество источников, в частности статистических. Это прежде всего данные переписей о численности, возрастном, национальном, социально-классовом и образовательном составе горожан. Для расчета суммарного коэффициента рождаемости и ожидаемой продолжительности жизни проведена кропотливая работа по сбору архивных сведений о рождаемости и смертности по возрасту за примыкающие к переписям годы по всем областям Западной Сибири. При этом автору удалось обнаружить и объединить громоздкие и многочисленные таблицы данных (за 30 лет) о межтерриториальном движении городского населения. Комплекс разнообразных источников позволил ему воссоздать детальную картину демографического развития городского населения Западной Сибири, в том числе разных категорий поселений (большое, среднее и малое) и их функциональных типов.

Большой интерес вызывает содержательная часть монографии. С одной стороны, численность горожан в абсолютном выражении увеличилась значительней, а их доля в населении повысилась почти так же, как и в РСФСР в целом. С другой же стороны, обнаружена значительная специфика урабанизационных процессов, которая скрывалась за внешним сходством демографических тенденций. Уже при приближенном рассмотрении 
выявлено, что к началу изучаемого периода крупные города играли очень большую роль в системе городского расселения, в них проживало около 2/3 всего городского населения, чего не наблюдалось в других экономических районах. За 30 лет эта доля не только не повысилась, как в России в целом, но даже несколько снизилась. Тщательное изучение экономической и градообразовательной динамики выявило, что этому способствовали формирование ЗСНГК, частые административные преобразования сел в поселки городского типа, снижение роли угольной промышленности, сдерживание на государственном уровне роста больших городов. В результате значение средних городов заметно возросло, а малых -уменьшилось не столь значительно, как в РСФСР.

В работе подчеркивается зависимость демографического развития от экономической базы и административного статуса городских поселений. Число жителей гораздо быстрее росло в административных центрах областей, тогда как в крупных индустриальных городах, таких, например, как Новокузнецк, Бийск, Рубцовск, Прокопьевск, АнжероСудженск повышалось медленней, а иногда даже уменьшалось.

Немалый интерес представляют разделы монографии, посвященные историческому генезису средних и малых городских поселений. Отмечается, что демографическое развитие большинства населенных пунктов, относящихся к этому типу и, прежде всего, районных центров, а также части индустриальных, шло намного медленнее. В это время в России отчетливо обозначилась тенденция к концентрации населения в крупных городах, так как малые города отличались ограниченным набором мест приложения труда. Это справедливо и в отношении Западной Сибири, где в начале рассматриваемого периода они в большинстве своем представляли узкоспециализированные поселения по добыче и переработке полезных ископаемых, в них располагались лишь мелкие предприятия по обслуживанию населения и переработке сельскохозяйственного сырья. Отставание в благоустройстве, недостаток образовательных и культурно-бытовых учреждений, слабое экономическое развитие приводили к оттоку населения, особенно молодежи.

Между тем масштабное освоение полезных ископаемых тюменского и томского севера потребовало создания новых поселков. Появилось значительное число городов, сформированных рядом с нефте- или газодобывающими предприятиями, их демографический рост за короткий срок оказался впечатляющим. Автор убедительно доказывает, что результатом такого разновекторного развития стало не снижение, а повышение совокупного экономического и демографического веса малых и средних городских поселений, что стало отличительной чертой урбанизации в Западной Сибири.

Существенным аспектом историко-демографических исследований является анализ возрастного состава населения. Во второй главе книги показано, что в местных городах шли, в общем, те же процессы, что и по всей России: последовательное старение населения сопровождалось уменьшением межполового дисбаланса, вызванного войной. На основе оценок среднего возраста населения автор монографии приходит к выводу, что за 30 лет возрастные характеристики жителей западносибирских городов и поселков городского типа относительно общероссийских показателей все-таки ухудшились, хоть и продолжали оставаться достаточно благоприятными. 
Важным достижением работы является выявление территориальных и категориальных изменений возрастного состава горожан. В частности, обнаружено углубление межрегиональной дифференциации в среднем возрасте, которая раньше была невелика (с 1,7 до 6,5 года). На основе материалов переписей показано, что за 30 лет увеличились также различия и между городскими поселениями. Если в 1959 г. разница между самым молодым и пожилым населением (Ялуторовск и Салехард) не превышала шести лет, то к 1989 г. она достигла 13,8 года (Кедровый и Гурьевский горсовет).

Следующим шагом стало изучение национальной структуры населения. Во втором параграфе второй главы показано, что в этническом составе жителей Западной Сибири доминирующие позиции сохранили народы, находящиеся на поздних этапах демографического перехода. Вместе с тем по мере расширения географии районов Советского Союза, охваченных демографической модернизацией, которая сопровождалась повышением миграционной мобильности местного населения, начинает расти представительство других национальностей. В монографии сделан вывод, что масштаб подобных перемен был тогда невысок и слабо отразился на естественном приросте. Сохранилось устойчивое доминирование русского этноса, удельный вес которого за 30 лет в городском населении почти не изменился.

В третьей главе работы рассматривается центральный вопрос демографических исследований - воспроизводство населения западносибирских городов. Несомненным достоинством научного труда стал расчет суммарных коэффициентов рождаемости и ожидаемой продолжительности жизни, на основе которых можно точнее определить тенденции рождаемости и смертности. На базе таких показателей стал возможен полноценный факторный анализ, тогда как при использовании общих коэффициентов из-за сильного влияния на него возрастной структуры повышалась вероятность ошибочных выводов. Здесь ключевой проблемой стало раскрытие особенностей завершающего этапа демографического перехода в Западной Сибири.

В книге убедительно доказывается, что специфика рождаемости в Западной Сибири определялась динамикой образовательного уровня, социально-классового состава, характером труда горожан, особенностями формирования сети городских поселений. Исходя из этого, О.Б. Дашинамжилов выделил две группы регионов с дифференцированными показателями воспроизводства. Так, наибольшая рождаемость (как и смертность) отмечена в Кузбассе и Тюменской области, где более низкий образовательный уровень сочетался с высокой долей рабочих и занятых преимущественно физическим трудом в составе населения и «раздробленностью» городской сети.

В противоположность этому рождаемость была ниже в Омской, Новосибирской и Томской областях - в регионах с более образованным населением, крупными областными центрами, сосредоточившими больше половины городских жителей, с высокой долей служащих с низкими репродуктивными установками. Отсюда логично вытекает утверждение, согласно которому преимущество в рождаемости Западной Сибири, по сравнению с РСФСР, оказалось небольшим, значительно меньшим, чем, например, рисует общий коэффициент. Автор солидарен с тезисом, выдвинутым ранее советскими демографами, что дифференциация в рождаемости между регионами, селом и городом с 
течением времени последовательно стиралась, и подтверждает это собственными расчетами. В заключение первого параграфа третьей главы он отмечает, что колебания рождаемости, вызванные изменением исторических условий, в городах Западной Сибири в силу специфики образовательного и социального состава населения и других причин носили более сильный характер.

В отличие от рождаемости историография изучения смертности 1960-1980-х годах не так значительна. Именно поэтому научные результаты таких трудов вызывают повышенный интерес. Проведена кропотливая работа по анализу и классификации факторов смертности. Несомненной заслугой автора являются подсчеты ожидаемой продолжительности жизни городского населения отдельных областей, мужчин и женщин, смертности по причинам смерти. В монографии доказано, что продолжительность жизни городского населения Западной Сибири была ниже, ее отставание от РСФСР со временем нарастало, более глубокими оказались и межполовые различия.

Автор исследования приходит к выводу, что это произошло вследствие взаимодействия нескольких факторов. Так, потребление алкоголя в Сибири имело свою специфику. В структуре продаж вино-водочных изделий доля пива и вина была меньше, чем в центрально-европейских или южных районах Советского Союза, а крепких напитков, сильнее воздействовавших на здоровье человека, больше. Одной из причин значительного количества смертей от несчастных случаев, отравлений и травм стало развитие отраслей народного хозяйства, отличавшихся высоким травматизмом среди работников (например, добывающая промышленность, строительство). Очевидно, что некоторый вклад внес уровень образования, который в Западной Сибири был традиционно ниже, чем в РСФСР в целом.

Вышеупомянутый тезис о существовании местных условий, влияющих на процессы воспроизводства, дополняется анализом специфических региональных факторов. Повышение возрастных коэффициентов смертности в трудоспособных когортах было обусловлено промышленным ростом в северных районах, где строительство жилья и других объектов социальной инфраструктуры происходило с задержками. В то же время сильному увеличению смертности в Западной Сибири препятствовала структура городских поселений в регионах, где доминировали большие города, лучше развито здравоохранение, в социальной структуре была высока доля служащих и занятых преимущественно умственным трудом. В конечном счете, рождаемость в Западной Сибири оказалась немного выше, а средняя продолжительность жизни несколько ниже, чем в РСФСР. Из этого сделан логичный вывод, что демографический переход здесь шел с некоторым запозданием, хотя динамика процесса в общих чертах была схожа с общероссийской.

Серьезный акцент был сделан на изучении пространственных перемещений населения. В хозяйственном освоении восточных районов значение миграций было очень высоким. Базовые параметры пространственных перемещений в Западной Сибири уже были изучены в других работах. Ключевой задачей четвертой главы, посвященной этой проблеме, стал анализ миграционного оборота, перемещений в разных категориях городских поселений и ежегодных межтерриториальных направлений миграций. 
Из текста монографии видно, что автор высоко оценивает значение миграционных процессов в пополнении городских контингентов, их ключевую роль в формировании местной специфики урбанизационного перехода. Например, он отмечает, что в 1960-е годы во время сильного оттока населения из восточных районов, в том числе и из Западной Сибири, размеры механического прироста населения городов падали. При этом убыль населения, характерная для деревни, затронула также и часть городских поселений, в основном поселков городского типа, а доля больших городов в миграционном потоке увеличивалась. Активизировались перемещения населения в регионы с высокоразвитой социальной инфраструктурой и диверсифицированной экономикой - на Украину, в центральные районы России. Значительный отток шел также в Северокавказский экономический район, Казахстан и Среднюю Азию.

В то же время увеличение государственных капитальных вложений в Западную Сибирь, как это было в 1970-1980-е годы, опережающие темпы ее индустриального роста, внедрение повышающих коэффициентов к заработной плате позволяли нивелировать действие негативных факторов, способствующих оттоку населения (климат и социальная сфера). Вместе с появлением новых городских поселений существенно повысился механический прирост населения, прежде всего в средних и малых городах. В это время наблюдался приток населения со всего Советского Союза, особенно высоким он был из Уральского, Поволжского, Восточносибирского экономических районов, из Казахстана и Украины. Таким образом, обосновывается положение о том, что если в России в целом в 1960-1980-е годы сальдо миграции городов и поселков городского типа последовательно сокращалось, то в Западной Сибири оно испытывало сильные колебания.

В заключение О.Б. Дашинамжилов констатирует, что интенсивный этап урабанизационного перехода в Западной Сибири обладал явными отличительными чертами. Нелинейное социально-экономическое развитие привело к тому, что затухание демографического роста городов носило непоследовательный, волнообразный характер. Урбанизация в 1960-1980-е годы дольше сохраняла экстенсивные черты (большие масштабы роста численности городского населения; не сокращение и даже повышение миграционного прироста населения городов; высокая интенсивность градообразования; опережающий рост горожан не в больших, а в малых и средних городах). Во многом из-за этого демографические последствия постсоветского кризиса в Западной Сибири оказались более тяжелыми, чем в центрально-европейских районах России.

Завершает монографию большое количество интересных приложений, которые гармонично дополняют представленную в книге информацию. В них содержаться расчеты и статистические сведения, позволяющие показать динамику численности, рождаемости, смертности, возрастного состава, миграций в отдельных областях и городах в 1959-1989 годы.

В заключение хотелось бы отметить, что рецензируемая книга является крупным шагом на пути изучения ретроспективных процессов народонаселения. Она представляет собой удачный синтез теоретико-методологических подходов и методов двух наук истории и демографии. Именно поэтому О.Б. Дашинамжилову удалось получить любопытные результаты, которые будут интересны специалистам по отечественной 
истории, демографии, урбанистике, этнологии, регионоведению. Практическая значимость исследования состоит в возможности использования выводов монографии при подготовке обобщающих трудов по истории России и Сибири, учебно-методической литературы. Книга может стать полезным вспомогательным материалом при выработке стратегии хозяйственного освоения малообжитых районов. Ее положения могут быть использованы в практической деятельности государственных органов власти при формировании социальной и демографической политики.

\section{ЛИТЕРАТУРА}

Дашинамжилов О.Б. (2018). Городское население Западной Сибири в 1960 - 1980-е годы: Историко-демографическое исследование. Новосибирск: Наука; Изд-во СО РАН. $368 \mathrm{c}$. 


\title{
THE URBAN POPULATION OF WESTERN SIBERIA \\ Review of the book «The Urban population of Western Siberia in the \\ 1960 through the 1980s: a historical demographic study» \\ GENNADY KORNILOV
}

\begin{abstract}
The book examines the demographic results of the urban transition in Western Siberia in conditions of stable social economic and political development of the country after the social catastrophes and cataclysms of the first half of the 20th century. Based on rich resource materials, it analyzes the development of large, average and small urban settlements, as well as the dynamics of population size, national composition, ethnodemographic and population age structures. The main factors and causes of fertility and mortality fluctuations and the distinctive features of the ethno-demographic transition are revealed through the study of the demographic modernization of Western Siberia. Great attention has been paid to population migration, including in and between different categories of urban settlement.
\end{abstract}

Key words: historical demography, Siberia, population reproduction, migration.

GENNADY KORNILOV (genakorn@mail.ru), INSTITUTE OF HISTORY AND ARCHEOLOGY OF THE URAL BRANCH OF RAS, RUSSIA.

DATE RECEIVED : JULY 2019.

\section{REFERENCES}

Dashinamzhilov O.B. (2018). Gorodskoe naselenie Zapadnoj Sibiri v 1960-1980-e gody: Istoriko-demograficheskoe issledovanie [The Urban population of Western Siberia in the 1960 through the 1980s: a historical demographic study]. Novosibirsk: Nauka; Publishing House of the Siberian Division of the Russian Academy of Science. 368 p. (In Russ.). 